\section{NOTE ON \\ TWO CASES OF PERNICIOUS ANAEMIa TREATED BY SALVARSAN. \\ BY}

BYROM BRAMWELL, M.D., P.R.C.P.E., F.R.S.E., SENIOR ORDINARY PHYSICIAN TO THE EDINBCRGH ROYAL INFIRMARY LECTURER IN. MEDICINE AND CLINICAL MEDICINE IN THO SCHOOL OF THE ROYAL COLLEGES, EDINBURGH.

Since I began to treat cases of pernicious anaemia by arsenic in the year $1875 \mathrm{I}$ have had a large experience of the disease. The results of my observations show: That in a large proportion of cases marked improvement, and, in many cases, temporary cure, result from the arsenical treatment; that the improvement is greatest in first attacks and in cases in which the patient can take large doses of arsenic ; but that in the great majority of cases, notwithstanding the arsenical treatment, relapses occur, and death ultimately takes place.

The term " pernicious," in my opinion, correctly repre. sents the tendency of the disease notwitbstanding all modern plans of treatment. When Ehrlich introduced his "606" (arseno-benzole) for the treatment of syphilis, it occurred to me that the remedy might perhaps be usefal in the treatment of pernicious anaemia; I consequently decided to try it in that disease.

In the following two cases the ${ }^{\circ}$ patients were suffering from all the typical symptoms of pernicious anaemia. Under ordinary arsenical treatment (the maximum dose in one case 36 drops per diem, and in the other 27 drops per diem of Fowler's solution) considerable improvement occurred both as regards the condition of the blood and the general eymptoms.

The arsenic (Fowler's solution) was then discontinued for several days, the condition of the blood and of the patients remaining practically unchanged.

The treatment by salvarsan was then commenced; each patient has had four doses of the remedy ad. ministered intramuscularly. In both cases very marked and continued improvement has reeulted, both as regards the condition of the blood and the general symptoms (see below).

I do not wish to draw conclusions from two cases, or to attach too much importance to the beneficial results which have occurred in these two cases in which salvarsan has been administered; all I would say is that in them, notwithstanding the discontinuance of the ordinary arsenical treatment (Fowler's solution) and the administration of salvarsan, marked and continued improvement. has occurred: Whether this improvement is the result of the salvarsan or not will have to be decided by the observation of further cases, and particularly of cases in which no arsenic has been previously administered. But the im. provement in these two cases has been so marked as to justify a thorough trial of the remedy ("606") in this disease (pernicious anaemia)

The notes of the cases are as follows:

CASE r.

J. S., aged 49, married, electric hoist man, formerly a soldier, was admitted to the Edinburgh Royal Infirmary on October 12th, 1910, suffering from marked pervicious anaemia:
Previous History.

The patient first came under my observation in October, 1909 , as an out-patient; he was then suffering from pernicious anaemia, not very marked in degree. He was treated with arsenic, and rapidly recovered. He returned to - work, and remained fairly well until the beginning of October, 1910; he then got a chill, rapidly became markedly anaemic and very short of brsath; his feet swelled, etc.

The patient denies having ever suffered from venereal disease. The bridge of his nose is sunken. The disease of the bones of the nose developed spontaneously when he'was 18 years of age, and was, perhaps, the result of congenital syphilis ; there are, however, no other stigmata of that condition.

State on Admission to Hospital.

The patient presented all the typical symptoms of pernicious anaemia. The blood count was as follows: Red corpuscles, 1,035,000; haemoglobin, 30 per cent.; colour index, 1.5; whites, 7,800. Differential connt: Polymorphs, 56.6 per cent.; mononuclears, 41 per cent. (large 15 per cent., small 26 per cent.) eosinophiles, 2.3 per cent. The red corpuscles showed marked alterations in size and shape (poikilocy tosis), polychromasia and granular degeneration. No nucleated reds were seen.

The patient was very short of breath on exertion; his feet and ankles were oedematous; there were no retinal haemorrhages. The systolic blood pressure was $88 \mathrm{~mm}$. of mercury. Blowing systolic murmurs were present in the mitral, pulmonary, and aortic areas. The tongue was clean and moist. There had been no sore spots on the tongue or mouth. The patient had had no teeth for several years; his gums were perfectly normal; the false teeth which he wears had given rise to no irritation. The urine was pale in colour, specific gravity 1012, and contained no abnormal constituents.

Treatment and Results.

Rest in bed; milk diet; arsenic (Fowler's solution), commencing with 2 minims, three times daily. When the arsenic was increased to 4 minims three times daily, diarrhoea developed; this was, however, easily restrained (as I have found to be the case in other cases) by combining a small dose of morphine ( 5 minims of the liquor morphinae hydrochlor.) with each dose of the arsenic. The arsenic was gradually increased to 12 minims, three times daily. The patient improved considerably under this treatment as regards his general symptoms, appearance, and the condition of the blood.

On December 16th, when the Fowler's solution was stopped the red corpusclesnumbered $1,830,000$, the haemoglobin equalled 52 per cent., and the colour index was 1.44 .

From December 16th to 2lst no drugs were administered.

On December 21st the condition of the blood was: Red corpuscles, 1,720,000; haemoglobin, 50 per cent.; colour index, 1.4 . On this date the first dose of " 606 " ( $0.2 \mathrm{gram}$ ) was given, the remedy being injected into the left buttock. On January 5th and 19th and on February 9th the injections of "606" were repeated, 0.3 gram being given on each of these occasions.

Coincidentally with this treatment very marked improvement has occurred. The patient now (February 23 rd, 1911) looks and feels quite well. The blood count is as follows: Red corpuscles, 3,580,000; haemoglobin, 78 per cent.; colour index, 1.1. The white corpuscles, which before the administration of the " 606 " numbered 4,600, now number 8,000 per c.mm. The systolic blood pressure has increased to $135 \mathrm{~mm}$. of mercury.

Each injection was followed by inflamma,tory hardness and pain in the buttock, but by practically no constitutional disturbance. The first injection was made into the left, the second into the right, the third into the left, and the fourth in to the right buttock.

The condition of the blood at different dates is shown in Table I.

CASE II.

Mrs. E. P., aged 40, married, housewife, was admitted to the Edinburgh Royal Infirmary on November 15th. 1910, suffering from marked pernicious anaemia of four months' duration The disease commenced after the birth of her last child; this and her previous seven confinements have all been attended with considerable haemorrhage.

CASE I.-Pernicious Anaemia-Shouing the Results of Treatment.

\begin{tabular}{|c|c|c|c|c|c|c|c|c|}
\hline Date. & & Treatment. & Dose. & $\begin{array}{c}\text { Red } \\
\text { Corpuscles. }\end{array}$ & Haemoglobin. & $\begin{array}{l}\text { Colour } \\
\text { Index. }\end{array}$ & $\begin{array}{c}\text { White } \\
\text { Corpuscles. }\end{array}$ & $\begin{array}{c}\text { Blood } \\
\text { Pressure. }\end{array}$ \\
\hline October 12, 1910 & $\ldots$ & Arsenic begun & 2 m., t.i.d. & $1,035,000$ & Per Cent. & 15 & 7,800 & 88 \\
\hline December 16, 1910 & $\ldots$ & Arsenic stopped & 12 m., t.i.d. & $1,830,000$ & $\cdot 52$ & 1.44 & 4.400 & 102 \\
\hline December 21, 1910 & ... & First injection " 606 " & $0.2 \mathrm{gram}$ & $1,720,000$ & 50 & 1.47 & 4,600 & 100 \\
\hline January 5, 1911 & ... & Second injection " 606 " & 0.3 gram & $2,500,000$ & 68 & 1.3 & 5,600 & 130 \\
\hline January 19, 1911 & ... & Third injection " 606 " & $0.3 \mathrm{gram}$ & $2,960,000$ & 70 & 1.18 & 8.200 & 100 \\
\hline February 9, 1911 & ... & Fourth injection "606" & $0.3 \mathrm{gram}$ & $3,200,000$ & 72 & 1.1 & 9,000 & 118 \\
\hline February 20, 1911 & $\cdots$ & - & - & $3,380,000$ & 78 & 1.16 & 8,000 & - \\
\hline February 23, 1911 & $\cdots$ & - & - & $3,580,000$ & 78 & 1.1 & 8,000 & 135 \\
\hline
\end{tabular}


TABLE II.

CASE II.-Pernicious Anaemia-Showing the Results of Treatment.

\begin{tabular}{|c|c|c|c|c|c|c|c|c|}
\hline Date. & & Treatment. & Dose. & $\underset{\text { Corpuscles. }}{\text { Red }}$ & Haemoglobin. & $\begin{array}{l}\text { Colour } \\
\text { Index. }\end{array}$ & $\begin{array}{l}\text { White } \\
\text { Corpuscles. }\end{array}$ & $\begin{array}{c}\text { Blood } \\
\text { Pressure. }\end{array}$ \\
\hline November 15, 1910 & $\ldots$ & Arsenic begun & 2 m., t.i.d. & 990,000 & Per Cent. & 1.6 & 4,600 & 108 \\
\hline December 16, 1910 & $\ldots$ & Arsenic stopped & 9 m., t.i.d. & $1,460,000$ & 45 & 1.5 & 4,200 & 94 \\
\hline December 24, 1910 & ... & First injection “606” & 0.3 gram & $1,760,000$ & 52 & 1.48 & 3,000 & 102 \\
\hline January 7, 1911 & $\cdots$ & Second injection " 606 " & 0.3 gram & $2,450,000$ & 68 & 1.38 & 4,000 & 108 \\
\hline January 24, 1911 & $\ldots$ & Third injection " 606 " & $0.3 \mathrm{gram}$ & $3,125,000$ & 74 & 1.19 & 7,000 & 98 \\
\hline February 9, 1911 & $\cdots$ & Fourth injection " 606 " & 0.3 grem & $3,350,000$ & 78 & 1.16 & 7,600 & 98 \\
\hline February 18, 1911 & ... & 一 & - & $4,140,000$ & 88 & 1.07 & 7,600 & 102 \\
\hline February 21, 1911 & $\ldots$ & - & - & $4,020,000$ & 88 & 1.1 & 6,200 & - \\
\hline
\end{tabular}

Previous History.

Two years ago Professor Caird removed a tuberculous tumour from the sternum; otherwise she had enjoyed good health until the present illness commenced. Some three weeks before her admission she suffered from sore spots on the mouth. and tongue. For many years past her teeth have been extremely bad. There is no suspicion of syphilis, unless two misoarriages and the death of a child, aged 8 months, were due to syphilis. The patient has six children alive and well.

State on Admission to Hospital.

The patient was very pale ; during the past two years she has lost more than a stone in weight. There is a curious patch of herpes on the nose.

The condition of the blood was as follows: Red corpuscles, 990,000 ; haemoglobin, 30 per cent. ; colour index, 1.6 ; whites, 4,600. Differential count?: Polymorphs, 74 per cent.; mononuclears, 17 per cent. (large 6 per cent., small 11 per cent.) eosinophiles, 7 per cent.; basophiles, 2 per cent. The red corpuscles varied very greatly in size and shape. There were some nucleated reds; no granular degeneration or polychromasia.

Blowing systolic marmurs were present in the mitral, pulmonary, and aortic areas. The pulse numbered 100. The systolic blood pressure was $108 \mathrm{~mm}$. of mercury. The tongae was pale and clean; the teeth very bad. The urine was dark in colour, specifle gravity 1010 , and contained no abnormal constituents. There were no haemorrhages in the retina.

Treatment and Results.

The arsenical trestment was commenced on November 15th 2 minims of Fowler's solution three times deily. The dose of arsenic was gradually increased until December 16th, when the patient was taking 9 minims of Fowler's solution three time daily. On November 26th, 1910, a slight thrombosis developed in the lower part of the right calf, but this rapidly yielded to trestment.

On December 16th Fowler's solution was stopped. The red corpuscles then numbered $1,460.000$, the haemoglobin was 45 per cent., and the colour index 1.5. From December 16th to $24 \mathrm{th}$ no drugs were given.

On December 24th the red corpuscles numbered $1,760,000$ haemoglobin, 62 per cent. ; colour index, 1.48 .

On December 24th, January 7 th and 24th, and February 9th 0.3 gram of " 606 " was injected into the battock. Coincidentally with this treatment very marked improvement has occurred. The patient now (February 23rd) looks and feels quite well.

On February 21st the blood count was as follows: Red corpusoles, 4,020,000; haemoglobin, 88 per cent. ; colour index, 1.1 . "The white corpuscles, which before the administration of " 606 " numbered 3,000, now number 6,200. The systolic blood pressure has remained practically unaltered during the treatment.

Considerable hardness and tenderness in the buttock resulted from each injection, but there wss little or no constitutions disturbance except after the last, which was followed for a few days by a swinging temperature.

March 3rd. Since the last note there has been pain and pleuritio triction over the lower part of the left chest, and some painless enlargement of the glands in the neck.

The condition of the blood at different dates is shown in Table II.

IN a report to the Persian Sanitary Council, Dr. MacConaghy, the representative of the council in the Persian Galf, states that the sanitary facilities at BenderAbbas, Jask, Bouchir, Lingah and Mohammerah are relatively satisfactory. Each of these ports has a disinfecting apparatus, and at Bouchir there is also a Clayton installation for what is rather quaintly called the "deratisation" of ships. Bouchir also possesses a portable disinfector which can, when necessary, be sent to any point on the coast.

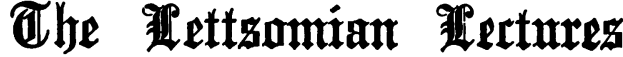

ON

\section{A REVIEW OF THE OPERATIONS F0R STONE IN THE MALE BLADDER.}

Delivered Before the Medical Socirty of London.

WILLIAM F. HASLAM, M.B., F.R.C.S., SURGEON, BIRMTNGHAM GENERAL HOBPITAL.

\section{LECTURE III.}

AN attempt was made by Deschamps in 1796 to revive the Marian operation on modified lines by what he termed a " mixed method." This resembled the lateral operation in the external incisions and the Marian in dilatation of the prostate and neck of the bladder, and he 8a,8, "who knows bat at some fatare time surgeons may not be tempted to return to this method?" In 1819 Sir Astley Cooper extracted a stone as large as a walnut by this mixed method; in 1830 it was adrocated by Dr. Buchanan of Glasgow, and in 1842 it was again brought forward by Dr. Willis. It received the name of "lithectacy," and then was heard of no more. By this time the lateral operation was becoming firmly established, and in 1853 Coulson says, "The lateral operation is now universally adopted, not only in this, but in all other countries, and hence we have prima facie reason for concluding that as a general method it is the best.". The rectangular staff of Buchanan was by some preferred to the ordinary curved staff as facilitating the opening of the urethra and the passage of the knife through the prostate, bat this in no way modified the steps of the lateral operation, nor was it at all widely used.

The first idea of the bilateral operation appears to have been due to $L_{\theta}$ Dran, who, in performing the lateral operation, sometimes found his internal incision was not sufficiently free. He therefore divided the right side of the prostate as well as the left. Sir Astley Cooper and others adopted the same practice. These operations, however, resembled the bilateral method only so far as the double incision of the prostate. The bilateral operation as a definite procedure was finally estab. lished by Dupuytren in 1824, and is described by William Coulson in his work on lithotrity and lithotomy published in 1853: "The patient is placed in the same position as for the lateral operation, an assistant holding the staff in an exactly vertical direction. The surgeon keeps the integument tense with the fingers of the left hand, and with a double.edged knife makes a semilunar incision in front of the anus. The incision com. mences on the right side, between the anus and the right ischium, ascends towards the raphe, and terminates on the left side, on a level with a point whence it set out. The middle point of the semilunar incision should traverse the raphe about ten lines in front of the anus. It involves the skin, the superficial perineal fascia, and the anterior fibres of the sphincter ani. The left forefinger is now passed into the wound, and guides the knife during a second incision which lays bare the membranous portion of the urethra; the nail now guides the point of the knife 